\title{
PERINATAL ASPHYXIA AND FETAL OUTCOME IN A TERTIARY HOSPITAL: ARE WE WINNING?
}

\section{B. Onankpa ${ }^{1}$, O. Ugege ${ }^{2}$.}

IDepartment of Paediatrics, Usmanu Danfodiyo University Teaching Hospital, Sokoto, Nigeria.

\section{Background}

Perinatal (intrapartum asphyxia) is the fifth largest cause of under-five deaths and it still poses a lot of challenges clinically especially in low resource settings. It is also the commonest cause of neurodevelopmental handicap in full term infants, expressively shown to have increased long term neurological disability and impairment.

\section{Objective}

This study was aimed at documenting the incidence of perinatal asphyxia and fetal outcome.

\section{Methods}

This two-year retrospective study was a review of all cases of attendant perinatal asphyxia admitted to Special Care Baby Unit (SCBU) of Usmanu Danfodiyo University Teaching Hospital, Sokoto, between March, 2005 and February, 2007. Data were obtained from maternal and neonatal case records. Results were analyzed and presented in simple percentages and frequencies.

\section{Results}

There was a total 5,224 deliveries during the study period, 174(3.3\%) of the babies were admitted to the SCBU with various degrees of perinatal asphyxia. The overall incidence was 35.6/1000 and 31.2/1000 live births for the years 2005 and 2006, respectively. 100(57.5\%) were males while, $74(42.5 \%)$ were females, with $\mathrm{M}$ : F ratio of $1.4: 1.85(48.9 \%)$ had severe perinatal asphyxia, 39(22.4\%) had moderate perinatal asphyxia while, 50(28.7\%) had mild perinatal asphyxia. 108(62.1\%) mothers attended antenatal clinic (ANC). Preterm deliveries were 64(36.8\%), term babies: $108(58.6 \%)$ while, post term babies were, 8(4.6\%). 54(31\%) babies died, 
41(75.9\%) had severe perinatal asphyxia. $10(18.5 \%)$ had moderate perinatal asphyxia while $3(5.6 \%)$ were mildly asphyxiated.

\section{Conclusions}

Birth asphyxia remains a leading cause of neonatal morbidity and mortality in Nigeria. The incidence of 31/1000 live births in our study is slightly more than earlier figures of 26.5/1000 live births reported from two studies in Nigeria The encountered rate could possibly represent the national average. There is the need, therefore, to improve on the present health care facilities especially in the areas of fetal monitoring and perinatal resuscitation 